\title{
The influence of anatomy app use on chiropractic students' learning outcomes: a randomised controlled trial
}

\author{
Amanda J. Meyer, Norman J. Stomski , C. Dominique Losco and Anthony J. Armson
}

\begin{abstract}
Background: Anatomy apps supplement traditional learning; however, it is unknown if their use can improve students' outcome. The present study examined whether the use of anatomy apps improved student performance on a neuroanatomy assessment.

Methods: Second-year anatomy students, enrolled in a Bachelor of Science with Chiropractic Major program, were randomly allocated to experimental and control groups in July 2015. Students completed the Self-Directed Learning Readiness Scale (SDLRS). The experimental group had access to iPads with four anatomy apps for three weekly classes (1.5 h each). One week after the last class, students were assessed by an online 30-question neuroanatomy test. Linear regression was used to examine the association between test scores and app use, gender, previous anatomy unit score and SDLRS scores. Students' views on apps were collected by focus group discussion immediately after the test.

Results: Completed questionnaires were obtained from $n=25$ control and $n=25$ experimental students. There was no association between app use and neuroanatomy assessment score $(\mathrm{B}=1.75,95 \% \mathrm{Cl}$ : $-0.340-3.840, p=0.099)$. Only previous anatomy unit score $(\mathrm{B}=0.348,95 \% \mathrm{Cl}$ : 0.214-0.483, $p<0.001)$ affected neuroanatomy assessment scores. Students favored apps with clinical images and features including identification pins, sliding bars and rotatable 3D images.
\end{abstract}

Conclusions: App use did not enhance learning outcomes in a second-year anatomy unit.

Keywords: Chiropractic, Anatomy, Student, App, Learning outcomes, Randomised controlled trial

\section{Background}

Teaching in anatomy is evolving, with a reduction in contact hours, increased student numbers, increased costs associated with cadavers and advances in technology, all driving change in the anatomy learning environment $[1,2]$. The use of advancing technology in anatomy education is supported, but it is noted that these tools are to complement how students explore, learn and collaborate in their learning environments and not to replace the existing practices [3-5]. A previous study examining the effect of a 3D neuroanatomical teaching tool (MRI data sets with 3D neuroanatomical structures overlaid) reported that $79 \%$ of experimental students strongly agreed that it helped to visualize 3D

\footnotetext{
* Correspondence: N.Stomski@murdoch.edu.au

School of Health Professions, Murdoch University, 90 South St, Murdoch, WA 6150, Australia
}

structures and spatial relationships in the brain [6]. The learning outcomes on a neuroanatomy assessment.

Computerized 3D teaching tools in anatomy education are not new, but they are now contained in mobile software applications (apps) that are easily accessible to students. Mobile technology devices (smartphones and tablets) are owned by the majority of students enrolled in anatomy units at Murdoch University [7]. Two-thirds of students owned one or more anatomy apps however majority used apps for less than 30 min per week, hich suggests that it may be beneficial to introduce rategies that enhance the use of anatomy apps [7] Hence, this study was designed to encourage a group of students to use anatomy apps in a loosely-guided self- 
directed manner during class time and examine whether it improved student outcomes on a summative neuroanatomy assessment.

\section{Methods \\ Sample}

Fifty seven students in a Bachelor of Science with Chiropractic Major program (chiropractic major: $n=53$; biomedical major: $n=2$; exercise physiology major: $n=2$ ) enrolled in CHI282 Human Anatomy II at Murdoch University (Semester 2, 2015) were randomly allocated to experimental $(n=31)$ and control $(n=26)$ groups in July 2015. A random number generator was used to create a randomization list. The group allocation was placed in sequentially numbered, opaque, sealed, envelopes. Research staff not involved with teaching the students handed the envelopes to students, who then immediately opened the envelope and notified the staff of group allocation.

All students were asked to complete the Self-directed Learning Readiness Scale (SDLRS) questionnaire during their first gross anatomy laboratory session. The SDLRS is a validated self-report instrument to assess students' readiness for self-directed learning [8]. Originally designed to measure the readiness of undergraduate nursing students for self-directed learning [8], the scale has since been used in a number of undergraduate educational settings such as medicine [9, 10]; paramedicine [11] and pharmacy [12]. The SDLRS questionnaire is a reliable and valid scale with 40 -items rated on a fivepoint Likert scale from 'strongly disagree' to 'strongly agree $[8,13]$. The maximum score is 200 and a score greater than 150 indicates that students have a high readiness for self-directed learning $[8,13]$.

\section{Intervention}

Students in the experimental group were given access to eight iPad(c) mini 2 tablets pre-loaded with neuroanatomy apps for three loosely-structured (learning objectives provided in the unit syllabus) gross anatomy laboratory sessions (1.5 h each). Each device had the following neuroanatomy apps: Brain and Nervous System Pro III [14], Essential Anatomy 5 [15]; Brain and Nervous Anatomy Atlas: Essential Reference for Students and Healthcare Professionals [16] and iSurf BrainView [17].

During the first session, experimental students were given access to the apps and were suggested to identify 55 structures in matching coronal sections of a cadaver brain and a T1-weighted MRI. During the second session, some students used the available apps to help construct a plasticine brainstem model. The third session was mainly focused on the pathways of the spinal cord tracts, for which no app was particularly suitable.
Students in the control group attended the three gross anatomy laboratory sessions and had access to all the same resources except the iPads.

\section{Anatomy assessment}

Students' knowledge of neuroanatomy was assessed using a closed-book 30 question image-based multiple choice test using the Moodle (Moodle Pty Ltd, Perth, Western Australia) quiz function. Students had $30 \mathrm{~min}$ to complete the summative assessment which was administered seven days after the third laboratory session. As this unit is the third and last anatomy unit taken by students, the majority of questions were higher-order (Levels 3 and 4) of the Blooming Anatomy Tool [18]. The assessment was marked automatically by Moodle Quiz. Marks were downloaded, and then matched with the SLDRS score and group number and then deidentified data prior to analysis.

\section{Focus group}

A focus group was conducted immediately after the summative assessment by a staff member who was not involved in the teaching of anatomy to the students. The focus group was held for 60 mins with seven students and was audio-recorded and notes were taken for clarification. To stimulate discussion, students were asked the following questions: (1) Do you think the use of apps enhanced your learning outcomes in the neuroanatomy wet labs? (2) Do you think there were any limitations of the apps that affected your learning outcomes in the neuroanatomy wet labs? (3) Which particular apps did you find most useful? Why? (4) Which particular apps did you find least useful? Why? and (5) Did you download and use any apps outside of the anatomy laboratory?

\section{Statistical analysis}

Data were analyzed using IBM $^{\oplus}$ SPSS $^{\oplus}$ Statistics package, version 21. All data were reported descriptively. Linear regression was used to examine the association between anatomy app use and neuroanatomy assessment scores. The students' gender, previous anatomy unit scores, and SDLRS scores were entered into the regression model as potential confounder factors as they had been found to influence educational app use in previous studies [19-21]. Cronbach's alpha was derived for the SDLRS scale.

\section{Results}

\section{Participants}

Completed questionnaires were obtained from 50 out of 57 student enrolled in the study. Two students did not consent to have their data included and five students had incomplete data. Participant characteristics are reported below in Tables 1 and 2 . 
Table 1 Neuroanatomy apps used in the gross anatomy laboratory

\begin{tabular}{|c|c|c|c|c|}
\hline Name of app & Developer & Version/Size & Positives & Negatives \\
\hline $\begin{array}{l}\text { Brain and Nervous Anatomy Atlas: } \\
\text { Essential Reference for Students } \\
\text { and Healthcare Professionals }\end{array}$ & Visible Body & 6.0.11/458 MB & $\begin{array}{l}\text { 3D } \\
\text { Rotation } \\
\text { One axial section Identify } \\
\text { spinal cord tracts }\end{array}$ & $\begin{array}{l}\text { Cost }(\$ 9.99) \\
\text { No spinal cord pathways }\end{array}$ \\
\hline Brain and Nervous System Pro & 3D4Medical.com, LLC & 3.8/758 MB & $\begin{array}{l}\text { Pins } \\
\text { Ability to slice through brain } \\
\text { Axial/sagittal/coronal views } \\
\text { Sliding bar to easily advance } \\
\text { through multiple images }\end{array}$ & $\begin{array}{l}\text { Cost }(\$ 9.99) \\
\text { No spinal cord pathways }\end{array}$ \\
\hline Essential Anatomy 5 & 3D4Medical.com, LLC & $5.0 / 645 \mathrm{MB}$ & $\begin{array}{l}\text { 3D } \\
\text { Rotation } \\
\text { Isolate/Hide structures } \\
\text { Information attached to } \\
\text { structure }\end{array}$ & $\begin{array}{l}\text { Cost }(\$ 24.99) \\
\text { Needed to hide all of the } \\
\text { cranium to get to brain } \\
\text { Quiz function very basic } \\
\text { No spinal cord pathways }\end{array}$ \\
\hline iSurf BrainView & Netfilter & 4.1.0/30.4 MB & $\begin{array}{l}\text { Free } \\
\text { MRI } \\
\text { Axial/sagittal/coronal views } \\
\text { Sliding bar }\end{array}$ & $\begin{array}{l}\text { Not all structures are } \\
\text { labeled }\end{array}$ \\
\hline
\end{tabular}

\section{Quantitative outcomes}

\section{Self-directed learning readiness scale}

Cronbach's alpha for the SDLRS total scale score was 0.88 . The mean total SDLRS score, administered prior to the intervention, was not different between the groups (control: 150.1, SD 13.5; experimental: 151.4, SD 12.0; $p=0.716)$.

\section{Intervention outcome}

The mean neuroanatomy assessments scores were not different between the groups (control: $63.3 \%$, SD $16.7 \%$; experimental: $70.0 \%$, SD $16.7 \%$; $p=0.106$ ). Table 3 displays the results of the linear regression. Neither self-directed laboratory-based anatomy app use, gender, nor SDLRS affected neuroanatomy assessment scores. The only factor that influenced neuroanatomy assessment scores was previous gross anatomy unit score $(\mathrm{B}=0.348,95 \% \mathrm{CI}$ : 0.214-0.483, $p<0.001)$. The overall model fit was $\mathrm{R}^{2}=0.472$.

\section{Qualitative outcomes}

\section{Focus group data}

Four common themes emerged from the focus group discussion:

Students' comments on the features of individual apps: Students highly praised the inclusion of identification

Table 2 Characteristics of the study participants

\begin{tabular}{llll}
\hline & $\begin{array}{l}\text { Experimental } \\
(n=25)\end{array}$ & $\begin{array}{l}\text { Control } \\
(n=25)\end{array}$ & $p$ value \\
\hline Mean age (years) & 22, SD 4 & 22, SD 6 & 0.954 \\
Males (\%) & $12(50 \%)$ & $10(40 \%)$ & 0.569 \\
$\begin{array}{l}\text { Mean previous anatomy } \\
\text { unit score (\%) }\end{array}$ & 66, SD 8\% & 65, SD 9 \% & 0.557 \\
\hline
\end{tabular}

SD standard deviation pins, sliding bars to advance through sections, isolate/ hide functions, ability to rotate 3D structures and quizzes for revision in anatomy apps. In particular, students said apps were useful for identifying and understanding the form of c-shaped structures in the brain. Lastly, students noted that app quiz functions were very basic and not at the same knowledge level as their summative assessment.

Students' comments on the use of individual apps: Students reported that they would have like more guidance on how to use the apps (training/familiarisation prior to session), and even reported that they would have preferred a tutor-led session (tutor instruction to the group using the apps) rather than being self-directed. Students admitted that they did not use anatomy apps at home as they were not prepared to pay for them on their own devices. Some students stated that they did not use anatomy apps much in class as it took time away from viewing cadavers which they knew would be on the summative assessment. Students acknowledged that they preferred using apps on tablets/computers rather than on smartphones due to a larger screen size and increased image resolution.

Students' comments on the content and graphics in apps: Students reported that the apps were helpful for

Table 3 Results of the multivariate linear regression analysis

\begin{tabular}{lccc}
\hline Variable & $\begin{array}{l}\text { Unstandardised } \\
\text { B coefficient }\end{array}$ & $\begin{array}{l}\text { 95\% Cl for } \\
\text { unstandardised } \\
\text { B coefficient }\end{array}$ & $p$ value \\
\hline Previous anatomy unit score & 0.348 & $0.214-0.483$ & $<0.001$ \\
Group Allocation & 1.75 & $-0.340-3.84$ & 0.099 \\
Gender & -0.754 & $-2.97-1.46$ & 0.496 \\
SDLRS score & -0.005 & $-0.099-0.090$ & 0.920 \\
\hline
\end{tabular}


identifying structures in specimens and clinical images that were not labelled in the anatomy laboratory. The graphics, particularly in the 3D4medical.com apps were of high quality and were easily manipulated through the touch screens. All the anatomy apps investigated lacked sufficient detail for spinal cord pathways and lesions, which were important concepts covered in the summative assessment.

Students' comments on the price of apps: Students noted that the price of apps was prohibitive ("...too expensive to purchase!"), however students also reported that they did not download free apps even when suggested by the course instructor.

\section{Discussion}

Self-directed use of neuroanatomy apps during a limited number of anatomy laboratory sessions was not significantly associated with students' performance on a neuroanatomy assessment. Students may have encountered a "technology learning curve" [19], whereby time learning to use the apps may have taken time away from learning the neuroanatomy. Additionally, the apps are limited to Level 1 (knowledge) and level 2 (comprehension) of the Blooming Anatomy Tool [18], whereas the summative neuroanatomy assessment contained many questions from Level 3 (application) and Level 4 (analysis).

In contrast to the present study, a recent study reported that anatomy students perceived that an iPad educational intervention improved laboratory and lecture performance [22]. However, this perceived improvement was based on the students' subjective views about their participation in lectures and laboratory sessions, and no pre/post intervention summative assessments were undertaken. Whether the intervention used in that study influences objective assessments needs to be established in further studies [22].

Another recent study found that the use of a digital interactive book, provided on an iPad, significantly improved anatomy students' summative assessment scores post resource [23]. However, that study differed from the present study since it was non-randomized, did not use a control group, and did not control for the influence of either grade point average or demographic factors [23]. Hence, these differences in research methods may account for the inconsistent findings between studies.

The only factor that influenced neuroanatomy assessment scores was students' previous gross anatomy unit score. Earlier reports also demonstrated that previous academic performance was shown to have a statistically significant relationship with student performance [24, 25]. Therefore, academics may be able to identify students at risk of failing due to past performance.

There was no association between SDLRS and neuroanatomy assessment scores in the present study. A weak correlation between SDLRS scores and academic performance has previously been reported in a study of 130 first year medical students in India [10]. Similarly, SDLRS scores were not related to knowledge levels in a study of 124 health profession students in the United States [26]. SDLRS score may not be an important predictor of academic performance when students are given learning objectives and open access to learning resources.

A number of limitations of the current study should be noted. Firstly, the neuroanatomy module comprised the first three weeks of the teaching semester which reduced the number of laboratory sessions where students had access to apps. Secondly students mostly used the apps during the initial laboratory session, and used them less during subsequent sessions as they did not have time to get over the "technology learning curve" before the summative assessment. Hence, it would be worthwhile to include "time spent using apps" as independent variable in further studies. Lastly, this study drew participants enrolled in one unit at a single institution who were mostly from one major which may limit the generalizability of our findings. A longer, larger, cross-institutional study may help to clarify whether use of anatomy apps can influence students' learning outcomes.

The practical implications for integrating the use of anatomy apps in the laboratory are five-fold: (1) anatomy instructors should be able to demonstrate how to use apps in a seamless, readily comprehensible, manner; (2) an adequate amount of time should be provided to students to familiarize themselves with the apps prior to use in the laboratory; (3) students can readily utilize apps for revision of basic anatomy; (4) 3D apps are particularly useful for identifying and understanding the form of c-shaped structures, such as the caudate nucleus and fornix and (5) there is a need for higher-order knowledge quizzes and inclusion of spinal cord pathways in apps featuring neuroanatomy.

\section{Conclusion}

Our findings indicated that short-term use of anatomy apps did not influence student learning outcomes. Given the limited number of studies conducted in this area, further studies are warranted to clarify whether use of anatomy apps can influence students' learning outcomes. In particular, such studies should examine whether time spent using educational apps, extent of instruction in using educational apps, and matching app content to learning outcomes, significantly influences anatomy learning outcomes.

\section{Abbreviation \\ SDLRS: Self-directed learning readiness scale}

Funding

Not applicable. 


\section{Availability of data and materials}

Data will not be shared as ethical approval was not granted for the public release of the data.

\section{Authors' contributions}

All authors contributed to the conceptualization of the study, analysis, and drafting of the manuscript.

\section{Competing interests}

The authors declare that they have no competing interests.

\section{Consent for publication}

Not applicable.

\section{Ethics approval and consent to participate}

This research project was approved by the Murdoch University Human Research Ethics Committee (Approval 2015/113).

\section{Received: 30 June 2016 Accepted: 5 October 2016}

\section{Published online: 01 December 2016}

\section{References}

1. Shaffer K. Teaching anatomy in the digital world. N Engl J Med. 2004; 351(13):1279-81.

2. Drake RL, McBride JM, Lachman N, Pawlina W. Medical education in the anatomical sciences: the winds of change continue to blow. Anat Sci Educ. 2009;2(6):253-9.

3. Lewis TL, Burnett B, Tunstall RG, Abrahams PH. Complementing anatomy education using three-dimensional anatomy mobile software applications on tablet computers. Clin Anat. 2014;27(3):313-20.

4. Smith DC, Slipper ML, Cecot DT, Border DS. Shaping Neuroanatomy Education in Medicine: Implementing an IPad Friendly E-booklet to Support Practical Based Learning. FASEB J. 2015;29(1 Supplement):209-16.

5. Gould DJ, Terrell MA, Fleming J. A usability study of users' perceptions toward a multimedia computer-assisted learning tool for neuroanatomy. Anat Sci Educ. 2008;1(4):175-83.

6. Drapkin ZA, Lindgren KA, Lopez MJ, Stabio ME. Development and assessment of a new 3D neuroanatomy teaching tool for MRI training. Anat Sci Educ. 2015:8(6):502-9.

7. Meyer AJ, Stomski NJ, Innes SI, Armson AJ. VARK learning preferences and mobile anatomy software application use in pre-clinical chiropractic students. Anat Sci Educ. 2016;9(3):247-54.

8. Fisher M, King J, Tague G. Development of a self-directed learning readiness scale for nursing education. Nurse Educ Today. 2001;21(7):516-25.

9. Kar SS, Premarajan KC, Ramalingam A, Iswarya S, Sujiv A, Subitha L. Selfdirected learning readiness among fifth semester MBBS students in a teaching institution of South India. Educ Health. 2014;27(3):289-92.

10. Abraham RR, Fisher M, Kamath A, Izzati TA, Nabila S, Atikah NN. Exploring first-year undergraduate medical students' self-directed learning readiness to physiology. Adv Physiol Educ. 2011;35(4):393-5.

11. Williams B, Brown T. A confirmatory factor analysis of the Self-Directed Learning Readiness Scale. Nurs Health Sci. 2013;15(4):430-6.

12. Deyo ZM, Huynh D, Rochester C, Sturpe DA, Kiser K. Readiness for selfdirected learning and academic performance in an abilities laboratory course. Am J Pharm Educ. 2011;75(2):25.

13. Hendry GD, Ginns P. Readiness for self-directed learning: validation of a new scale with medical students. Med Teach. 2009;31(10):918-20.

14. 3D4Medical.com. Brain and Nervous System Pro. In: IPad edn. San Diego: 3D4Medical.com; 2014

15. 3D4Medical.com. Essential Anatomy 5. In: iPhone, iPad, iPod touch edn. San Diego: 3D4Medical.com; 2014.

16. Inc AP. Brain and Nervous Anatomy Atlas: Essential Reference for Students and Healthcare Professionals. In: 6.0.11 edn. 2014. iPhone, iPad, iPod touch.

17. Netfilter. BrainView. In: 4.1.0 edn. 2013. iPhone, iPad, iPod touch

18. Thompson AR, O'Loughlin VD. The Blooming Anatomy Tool (BAT): A discipline-specific rubric for utilizing Bloom's taxonomy in the design and evaluation of assessments in the anatomical sciences. Anat Sci Educ. 2015: 8(6):493-501.

19. Sandholzer M, Deutsch T, Frese T, Winter A. Predictors of students' selfreported adoption of a smartphone application for medical education in general practice. BMC Med Educ. 2015;15:91.
20. Chen B, Denoyelles A. Exploring students' mobile learning practices in higher education. Educause Review. 2013.

21. Ellaway RH, Fink P, Graves L, Campbell A. Left to their own devices: medical learners' use of mobile technologies. Med Teach. 2014;36:130-8.

22. Raney MA. Dose- and time-dependent benefits of iPad technology in an undergraduate human anatomy course. Anat Sci Educ. 2016:9(4):367-77.

23. Stewart S, Choudhury B. Mobile technology: Creation and use of an iBook to teach the anatomy of the brachial plexus. Anat Sci Educ. 2015;8:429-37.

24. Potolsky L, Cohen J, Saylor C. Academic Performance of Nursing Students: Do Prerequisite Grades and Tutoring MAKE A DIFFERENCE? Nurs Educ Perspect. 2003;24(5):246-50.

25. Peterson CA, Tucker RP. Medical gross anatomy as a predictor of performance on the USMLE Step 1. Anat Rec. 2005;283B(1):5-8.

26. Gould K, Sadera W, McNary S. Comparing changes in content knowledge between online ProBLem based learning and traditional instruction in undergraduate health professional students. MERLOT J Online Learn Teach. 2015;11(1):74-86.

\section{Submit your next manuscript to BioMed Central and we will help you at every step:}

- We accept pre-submission inquiries

- Our selector tool helps you to find the most relevant journal

- We provide round the clock customer support

- Convenient online submission

- Thorough peer review

- Inclusion in PubMed and all major indexing services

- Maximum visibility for your research

Submit your manuscript at www.biomedcentral.com/submit
C Biomed Central 